\title{
IMPLEMENTAÇÃO DO LEPEM: LABORATÓRIO DE ESTUDOS E PESQUISAS EM EDUCAÇÃO MATEMÁTICA DA URI ERECHIM
}

Lepem implementation: laboratory of studies and research in mathematical education at URI Erechim

\author{
Simone Fátima Zanoello ${ }^{1}$
}

${ }^{1}$ Doutora em Ensino de Ciências e Matemática pela ULBRA. Docente da Universidade Regional Integrada do Alto Uruguai e das Missões, Erechim, RS.E-mail: simonez@uri.com.br

Data do recebimento: 27/03/2020 - Data do aceite: 01/08/2020

\begin{abstract}
RESUMO: Acredita-se que o Laboratório de Matemática é uma sala-ambiente que pode auxiliar professores e alunos na construção do conhecimento. Ciente disso, no ano de 1992, a Universidade Regional Integrada do Alto Uruguai e das Missões - URI Erechim iniciou a implementação de um Laboratório de Matemática na instituição, o qual foi denominado "Laboratório de Estudos e Pesquisas em Educação Matemática - LEPEM”. O presente artigo tem como objetivo relatar a história da implantação do LEPEM, bem como seu funcionamento, sua estrutura e as atividades nele desenvolvidas. Ao longo dos anos, o LEPEM adquiriu recursos didáticos e construiu inúmeros materiais e jogos. Hoje ele é considerado um espaço indispensável na instituição, sendo utilizado por alunos da Educação Básica, dos cursos de Licenciatura e Engenharia. Além disso, é um espaço onde se realizam cursos de formação para professores da educação básica, como também projetos de extensão e de iniciação científica.
\end{abstract}

Palavras-chave: URI Erechim. Laboratório de Matemática. Implementação. Estrutura. Funcionamento. Atividades Desenvolvidas.

ABSTRACT: It is believed that a Mathematics Laboratory is an environ-
ment that can assist teachers and students in the construction of knowledge.
Based on this, in 1992 Universidade Regional do Alto Uruguai e das Mis-
sões - URI Erechim started the implementation of a Mathematics Laboratory
at the institution, which was called Laboratory of Studies and Research in 
Mathematical Education - LEPEM. This article aims to report the history of the implementation of LEPEM in the institution, how it works, its structure and the activities developed in this environment. Over the years, LEPEM has acquired educational resources and has built numerous materials and games. Nowadays, it is considered an indispensable space in the institution, being used by Basic Education students, Undergraduate and Engineering Courses. In addition, it is a space where training courses are held for Basic Education teachers, extension projects and scientific research.

Keywords: URI Erechim. Mathematics Laboratory. Implementation. Structure. Operation. Developed activities.

\section{Introdução}

Vivemos em uma sociedade que passa por constantes mudanças e, nesse contexto, a escola precisa preparar os alunos para essas transformações. A sociedade busca por cidadãos que tenham competências matemáticas. De acordo com a Base Nacional Comum Curricular (BRASIL, 2017, p. 265) "O conhecimento matemático é necessário para todos os alunos da Educação Básica, seja por sua grande aplicação na sociedade contemporânea, seja pelas suas potencialidades na formação de cidadãos críticos, cientes de suas responsabilidades sociais".

Ainda, de acordo com a Base Nacional Comum Curricular - BNCC (2017), à medida que as pessoas se integram em uma sociedade da informação, em crescente globalização, é de suma importância que a educação se volte para o desenvolvimento de competências de comunicação, resolução de problemas e tomada de decisões, habilitando os alunos a interferir, criar, aperfeiçoar conhecimentos e valores, e saber trabalhar cooperativamente.

Cabe, pois, à escola proporcionar aos alunos situações em que eles possam empregar a Matemática tanto em sua vida pessoal quanto profissional. A Matemática, nesta perspectiva, contribui para o desenvolvimento do pensamento lógico e dedutivo, da capacidade de resolver problemas, de analisar e enfrentar situações diferentes, desde que o seu ensino propicie ao aluno situações em que possa refletir, analisar e tomar decisões, não simplesmente recebendo tudo pronto e acabado. Para que isso ocorra, segundo Oshima e Pavanello (2011, p. 2), é necessário que o professor possua:

[...] não só um conhecimento profundo dos conteúdos, como também de procedimentos de ensino mais eficazes para promover a aprendizagem de seus alunos, procedimentos estes que não se reduzam somente a quadro, giz e livros.

Faz-se necessário buscar alternativas metodológicas que auxiliem no desenvolvimento dos conteúdos matemáticos e que permitam ao aluno desenvolver essas competências. Nesse âmbito, evidencia-se a importância do Laboratório de Matemática, que pode ser considerado um aliado no processo de ensinar e aprender a referida disciplina, auxiliando na construção e no desenvolvimento do conhecimento matemático.

Diante disso, o presente artigo tem como objetivo refletir sobre a concepção de Laboratório de Matemática, relatar a história da 
implantação do Laboratório de Matemática na URI Erechim, bem como apresentar como é o seu funcionamento, sua estrutura e as atividades desenvolvidas no referido espaço. A fim de atender tal objetivo, o presente artigo está estruturado em duas seções: Laboratório de Matemática e História, Estrutura, Funcionamento e Atividades desenvolvidas no LEPEM, da URI Erechim.

\section{Laboratório de matemática}

Ao pensar em um Laboratório de Matemática numa escola, pode-se imaginar uma sala-ambiente, um armário ou um canto da própria sala de aula. Segundo Perez (1993), tradicionalmente, um Laboratório é um lugar onde se realizam experimentos com materiais didáticos. Isso quer dizer que, como os Laboratórios de Física, Química e Biologia, o Laboratório de Matemática também deve ser um local de experimentação, onde o próprio professor possa dinamizar e enriquecer suas aulas, tornando a aprendizagem mais eficaz para os alunos. De acordo com Lorenzato (2006, p. 7), Laboratório de Matemática:

\section{[...] é uma sala-ambiente para estruturar, organizar, planejar e fazer acontecer o pensamento matemático, é um espaço para facilitar, tanto ao aluno como ao professor, questionar, conjecturar, procurar, experi- mentar, analisar e concluir, enfim, apren- der e principalmente aprender a aprender.}

Para Ewbank (1977), o Laboratório de Matemática representa um local, um processo, um procedimento. No sentido de lugar, é uma sala estruturada para experimentos e atividades práticas envolvendo a Matemática. Também caracteriza uma abordagem utilizada em sala de aula, onde os alunos trabalham de maneira informal, discutindo e escolhendo seus materiais e métodos, descobrindo a Matemática por eles mesmos.
As concepções acima referem-se a salas-ambiente, específicas para o Laboratório de Matemática, mas deve-se lembrar que nem todas as escolas possuem um espaço próprio para tal. Sendo assim, grande parte das instituições de ensino tem como Laboratório um armário, um depósito, ou até mesmo guardam os materiais na própria sala de aula. Lorenzato (2006) indica que o Laboratório de Matemática pode ser uma sala de aula, uma biblioteca, desde que seja um lugar da escola onde os professores estejam empenhados em fazer com que a Matemática fique mais compreensível aos alunos. Em suas palavras:

Para muitos professores, todas as salas de aula e todas as suas aulas devem ser um laboratório onde se dão as aprendizagens da matemática. Essa é uma utopia que enfraquece a concepção possível e realizável do LEM, porque ela pode induzir professores a não tentarem construir o LEM num certo local da escola em que trabalham, seja este numa sala, num canto ou num armário (LORENZATO, 2006, p. 7).

O mais importante é que o Laboratório de Matemática se torne um aliado no processo de ensinar e de aprender Matemática, facilitando o entendimento dos conteúdos, tornando-se um ambiente de plena construção do conhecimento matemático, e também um trabalho gratificante para o professor.

É necessário pensar sobre a importância de construir um Laboratório de Matemática na escola, pois a sua utilização pode auxiliar o aluno que não gosta dessa disciplina a reverter a imagem negativa que possui em relação a ela. Lorenzato (2006, p. 34, grifo do autor) questiona: "Se for verdadeiro que 'ninguém ama o que não conhece', entãoa explicado porque tantos alunos não gostam da Matemática, pois, se a eles não foi dado conhecer a Matemática, como podem vir a admirá-la?". Ou seja, por esse ponto de vista, o Laboratório de Matemática pode 
proporcionar ao aluno conhecer a Matemática e produzir Matemática, bem como pode proporcionar aprendizagens para o aluno, contribuindo para diminuir essa aversão pela disciplina. Assim,

O Laboratório de Ensino de Matemática (LEM) em uma escola constitui um importante espaço de experimentação para o aluno e, em especial, para o professor, que tem a oportunidade de avaliar na prática, sem as pressões do espaço formal tradicional da sala de aula, novos materiais e metodologias, resultados de pesquisas disponibilizados na literatura [...], ampliando sua formação de modo crítico [...] (RÊGO; RÊGO, 2006, p. 41).

É importante ressaltar que o Laboratório de Matemática também é um espaço de experimentação para o professor. Corroborando com isso, Silva e Silva $(2004$, p. 2) afirmam que, no Laboratório, professores e alunos podem expandir a sua criatividade, dinamizar o trabalho e enriquecer as atividades, tornando o processo de ensino e de aprendizagem mais dinâmico, prazeroso e eficaz. Os mesmos autores salientam:

O laboratório, portanto, é um ambiente propício para estimular no aluno o gosto pela matemática, a perseverança na busca de soluções e a confiança na sua capacidade de aprender e fazer matemática. Além de contribuir para a construção de conceitos, procedimento e habilidades matemáticas, pode propiciar também a busca por relações, propriedades e regularidades, estimulando o espírito investigativo. Por isso, deve ser neste local da escola onde se respire Matemática o tempo todo e possa ser também um ambiente permanente de busca e descoberta (SILVA; SILVA, 2004, p. 2).

Ou seja, o Laboratório de Matemática deve ser um ambiente de plena aprendizagem onde o aluno tenha a oportunidade de descobrir suas próprias capacidades. Franzoni e Panossian (1999 apud REFOSCO; BASSOI, 2011, p. 3) enfatizam que o Laboratório de Matemática "[...] é um ambiente que propicia aos alunos a possibilidade de construção de conceitos matemáticos, além da análise e nova interpretação do mundo em que vivem".

Para Gonçalves (2011), o Laboratório de Matemática não constitui somente um espaço físico com diversos materiais concretos, mas também as atividades desenvolvidas nele, que darão vida ao local. $\mathrm{O}$ autor cita algumas atividades que podem ser desenvolvidas no Laboratório de Matemática: aulas dinâmicas, oficinas de Matemática, feiras de jogos matemáticos, apresentações de palestras, gincanas, minicursos, aulas de reforço escolar, sala de resolução de exercícios, sala para grupos de estudos formados por alunos, cursinhos preparatórios para concursos e vestibulares, campeonatos de damas, xadrez e outros jogos, bem como exposições de obras de arte ligadas ao conhecimento da Matemática.

É importante lembrar que Laboratório de Matemática não deve ser somente um local diferente para trabalhar com os alunos, tornar as aulas menos "conteudistas" ou simplesmente mudar de ambiente. O Laboratório deve ser um espaço de intensa experimentação, onde o aluno realmente possa aprender e crescer intelectualmente, tornando melhor a qualidade do ensino de Matemática em relação à construção do conhecimento. Conforme Ignatiév (1911 apud RÊGO; RÊGO, 2006, p. 43, grifo do autor), "[...] a independência mental, a reflexão e a criatividade não podem ser metidas em nenhuma cabeça [...]", ou seja, é através de experimentações que o aluno aprenderá o quanto é bom descobrir, enfrentar os desafios e saber vencê-los, aprendendo por seu próprio esforço. E o Laboratório pode ser auxiliar nessa tarefa, proporcionando ao aluno experiências com materiais que faci- 
litarão a aprendizagem. Mas é importante salientar que o professor tem um papel muito importante em todo este processo de experimentação e reflexão, pois cabe a ele estimular o aluno a refletir, pensar, criar e explorar os materiais, tornando-se um mediador entre o aluno e o conhecimento. Cabe, ainda, ao professor ter clareza de que o conhecimento não pode ser construído de um dia para o outro; ao contrário, é um trabalho de longo prazo e, mesmo depois de pronto, necessita de constante atualização, o que, por sua vez, exige um esforço coletivo dos professores e também dos alunos.

\section{É difícil para o professor construir sozinho o LEM e, mais ainda, mantê-lo. Convém que o LEM seja consequência de uma aspiração grupal, de uma conquista de professores, administradores e de alunos. Essa participação de diferentes segmentos da escola pode garantir ao LEM uma diferenciada constituição, por meio das possíveis e indispensáveis contribuições dos professores de história, geografia, educação artística, educação física, português, ciências, entre outros (LORENZATO, 2006, p. 8).}

Muitos professores argumentam ser difícil construir um Laboratório de Matemática, outros afirmam não ter condições para a compra de materiais para a implementação. Argumentos como esses podem ser formas de esconder certo desinteresse, desmotivação e/ ou acomodação por parte dos docentes. Para Lorenzato (2006), lecionar em uma escola que não possui Laboratório de Matemática é a oportunidade ideal para construí-lo com a participação dos próprios alunos, utilizando sucatas e diminuindo custos.

É importante que os professores considerem a faixa etária para a qual o Laboratório de Matemática se destina, pois é a partir dessa informação que poderá ser feita a seleção dos materiais que irão compô-lo.
Lorenzato (2006) explica que se o Laboratório de Matemática se destina a crianças de Educação Infantil, deve possuir materiais que auxiliem à correspondência, comparação, classificação, sequenciação, seriação, inclusão e conservação, além de percepção espacial e noção de distância. Se o Laboratório se destina ao Ensino Fundamental, os materiais deverão possibilitar ao educando ampliação de conceitos, apoio na descoberta de propriedades, percepção da necessidade do uso de símbolos e compreensão de algoritmos, bem como deve contar com material que desafie o raciocínio lógico-dedutivo em aritmética, geometria, álgebra, trigonometria e estatística. Já para o Ensino Médio, pode ter questões de vestibulares, desafios de raciocínio combinatório ou topológico, problemas de aplicação matemática, artigos de jornais e revistas. Assim, construir um Laboratório de Matemática não é somente ter uma sala, mas uma sala com muitos materiais, tais como livros didáticos e paradidáticos, revistas, jornais, artigos, problemas, sugestões de atividades, falácias, curiosidades, réguas, tesouras, colas, calculadoras, lápis de cor e de escrever, compassos, transferidores, esquadros (em acrílico e em madeira), dados, botões, sólidos geométricos, ábacos, quadro de tiras, xadrez, damas, dominós, quebra-cabeças, sucatas, jogos diversos destinados à educação infantil, séries iniciais, ensino fundamental e ensino médio, que possibilitem o alcance dos reais objetivos do ensino.

É importante ressaltar, como o faz Gonçalves (2011), que todo esse material deve ser encarado como um meio para uma aprendizagem significativa e não como um fim, sendo importante ter um conhecimento prévio sobre eles, ou seja, de como trabalhar com eles, os benefícios que trazem e os cuidados para a adequada utilização.

No próximo item será relatada, de forma sucinta, a história da implementação do Laboratório de Matemática da URI Erechim. 


\section{História, estrutura, funcionamento e atividades desenvolvidas no LEPEM da URI Erechim}

No ano de 1992, elaborou-se o primeiro projeto para criação de um Laboratório de Matemática na URI Erechim. O Laboratório foi implementado com o nome de Laboratório de Estudos e Pesquisas em Educação Matemática - LEPEM e foi criado com o objetivo de oportunizar a construção do conhecimento matemático dos alunos da pré-escola ${ }^{1}$ ao ensino superior.

Para isso, desenvolveram-se atividades que envolviam a construção de materiais didático-pedagógicos auxiliares à construção de conceitos matemáticos; realizaram-se reuniões de estudos tendo em vista o aprofundamento teórico necessário ao desenvolvimento das atividades desenvolvidas pelo laboratório; assessoramento aos alunos dos cursos de Pedagogia Séries Iniciais ${ }^{1}$, Ciências Licenciatura Curta, Matemática Licenciatura Plena, professores da rede pública estadual e municipal e professores da Escola de $1^{\circ}$ e $2^{\circ}$ Graus da FAPES ${ }^{2}$ (Fundação Alto Uruguai para Pesquisa e Ensino Superior). Dentre as atividades desenvolvidas com os professores da rede pública da região da $15^{\circ}$ Coordenadoria Regional de Educação (CRE), do estado do Rio Grande do Sul, destacam-se o Projeto ACOMECIM (Ação Conjunta para a Melhoria do Ensino de Ciências e Matemática). A Figura 1 mostra a primeira sala onde se implementou o LEPEM da URI Erechim.

Em 1995, elaborou-se um segundo projeto, com o objetivo de criar a infraestrutura necessária ao desenvolvimento de atividades voltadas para a pesquisa, a extensão e a formação de professores nas áreas de Matemática e Educação Matemática na referida instituição. Nesse mesmo ano, o Laboratório de Matemática mudou-se para uma sala ampla onde, a partir de 1996, teve uma primeira bolsista, a qual tinha, entre outras, a tarefa de construir materiais didáticos para o Laboratório.

Figura 1 - Primeira sala onde se implementou o LEPEM da URI Erechim

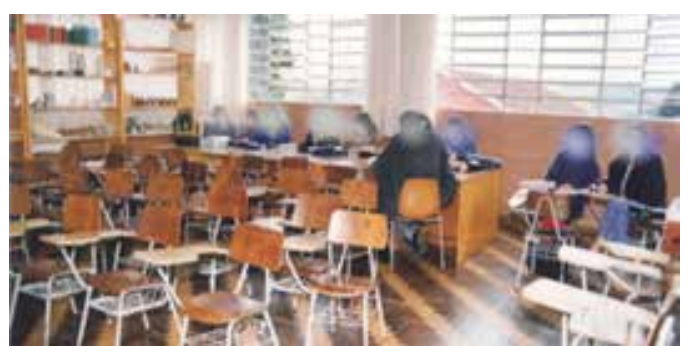

Fonte: Arquivos da URI Erechim

Na Figura 2, apresenta-se a sala onde está localizado o LEPEM, de 1996, até os dias de hoje.

Figura 2 - Sala onde está alocado o LEPEM da URI Erechim, atualmente
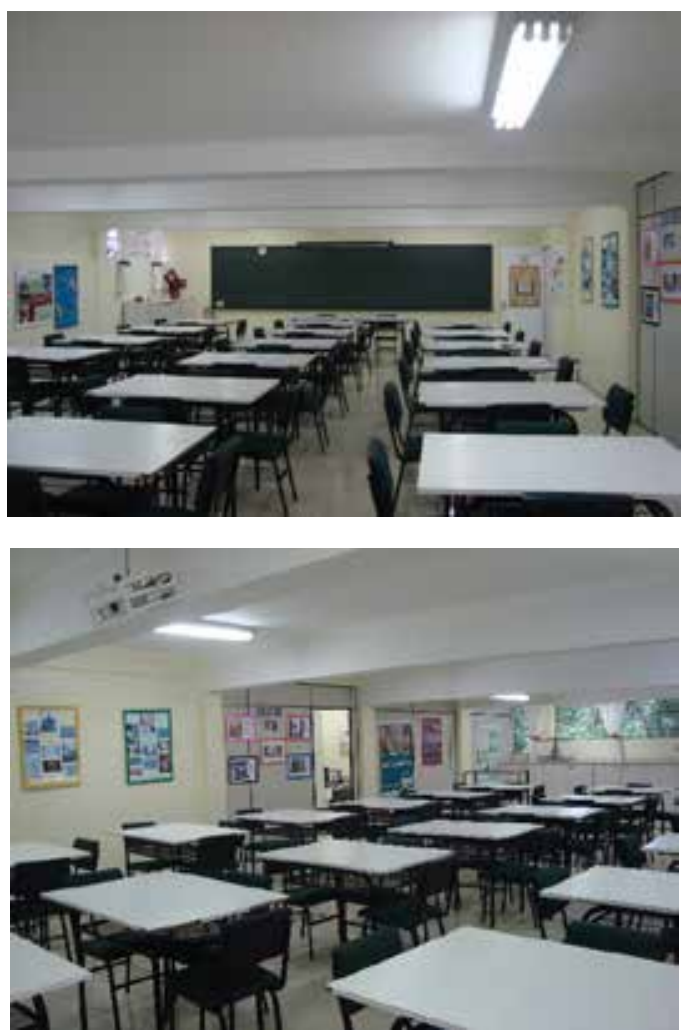


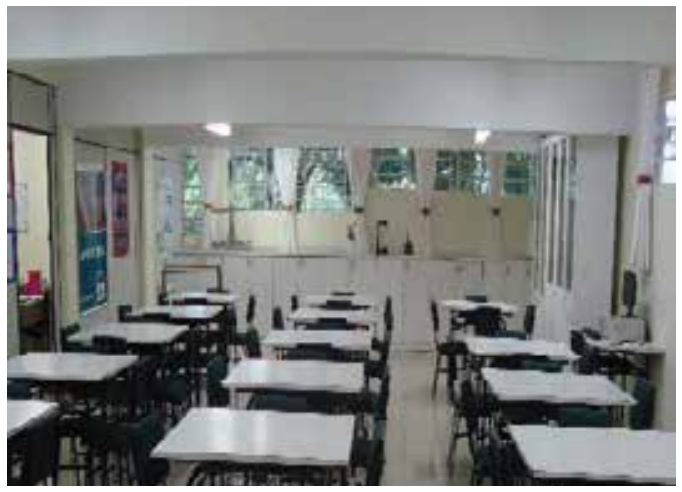

Fonte: A autora (2017)

Em 2007, a coordenadora do Curso de Matemática da época avaliou ser necessário que um professor do Departamento ficasse responsável pelo LEPEM, pois acreditava que o mesmo estava necessitando ser revitalizado. Na oportunidade, o espaço passou por profundas mudanças, pois verificou-se que possuía materiais didáticos estruturados incompletos, jogos matemáticos feitos sem esmero e com regras incompletas, inúmeros materiais que não eram de uso do Laboratório de Matemática acondicionados nos armários da sala.

A fim de atingir os objetivos propostos, a professora responsável, em conjunto com os estagiários do LEPEM, em um primeiro momento, realocaram todos os materiais que não eram de uso do laboratório, nos devidos locais; retiraram todos os materiais que estavam obsoletos e não teriam mais utilidade e os levaram para reciclagem; analisaram todos os materiais didáticos identificando os que estavam incompletos e providenciando as peças para completá-los. Analisaram-se também os jogos matemáticos que deveriam ser refeitos e/ou cujas regras deviam ser reescritas e, por fim, elaboraram uma listagem de materiais que julgavam essenciais estarem presentes no LEPEM. Para obter tais materiais contaram com a ajuda dos alunos do curso de graduação em Matemática, os quais foram incansáveis, participando ativamente de todas as campanhas realizadas.

Concluídas essas etapas, foram etiquetados todos os materiais, jogos e portas onde os mesmos foram acondicionados, conforme se pode observar na Figura 3.

Figura 3 - Jogos e materiais do LEPEM da URI Erechim

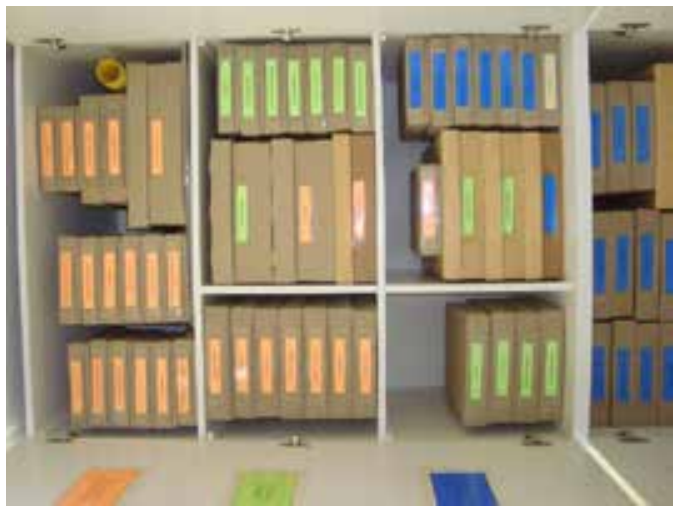

Fonte: A autora (2017)

Organizaram-se pastas descrevendo os materiais existentes no LEPEM, os jogos com as respectivas regras por séries, facilitando assim a decisão dos professores e dos alunos estagiários ao realizarem a escolha dos mesmos para suas aulas, e sugestões de como explorar os materiais estruturados existentes no LEPEM, pois constatou-se, em conversa informal, com professores da Escola Básica e alunos do Curso de Matemática da referida instituição, que os mesmos não conheciam alguns desses materiais ou não sabiam explorá-los (Figura 4).

O LEPEM tem como objetivo incentivar o aluno na busca e na construção do saber, oportunizando momentos lúdicos com recursos variados e realizando atividades diversificadas, desafiadoras, significativas, favorecendo a estruturação do pensamento e o desenvolvimento lógico; envolver o acadêmico na aprendizagem, tornando-o sujeito 
atuante em busca de novas descobertas que gerem conhecimento significativo; elaborar e construir materiais didático-pedagógicos destinados a alunos e professores de Matemática; proporcionar momentos de reflexão aos professores da rede pública municipal e estadual, sobre a importância da implementação do Laboratório de Matemática nas escolas, para o processo de ensino e aprendizagem de Matemática e assessorá-los na implementação do Laboratório de Matemática em sua escola.

Figura 4 - Pastas onde são descritos os jogos existentes no LEPEM
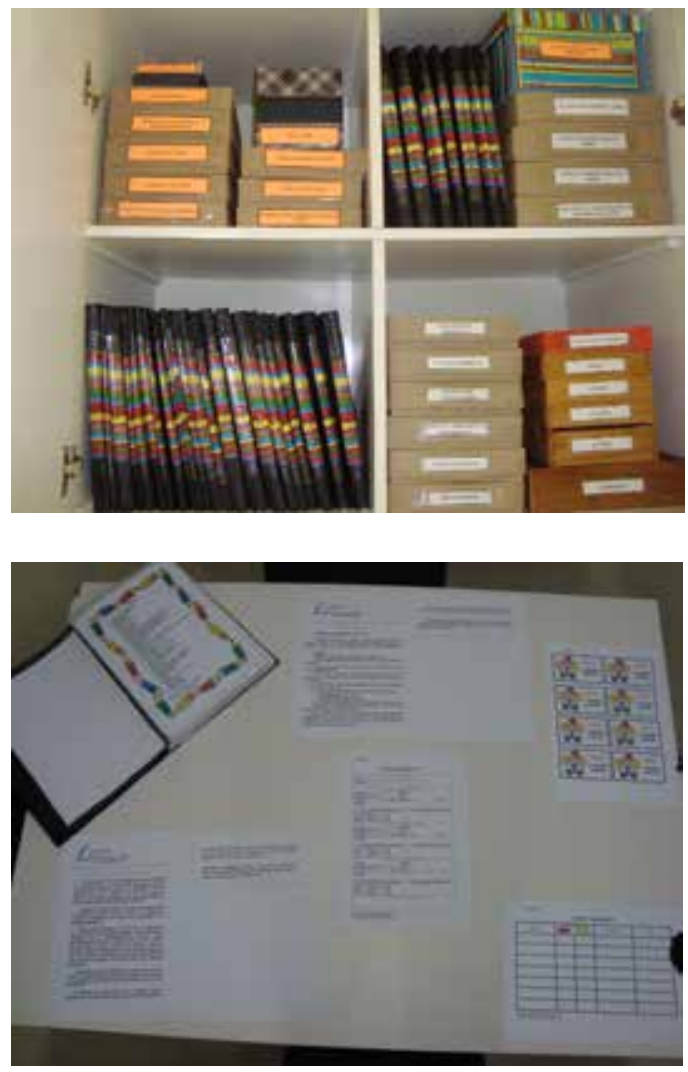

Fonte: A autora (2017)

Para fins de relato, materiais existentes no LEPEM são organizados em jogos, materiais estruturados, "problemoteca", desafios e recursos diversos.
O LEPEM possui uma vasta quantidade de jogos, os quais possibilitam atender alunos da Educação Infantil ao Ensino Superior, contemplando as quatro grandes áreas da Matemática: Números e Operações, Geometria e Medidas, Álgebra e Funções e Tratamento da Informação, além de possuir jogos como xadrez, damas/trilha, general, baralho espanhol e pega-varetas.

Dentre os materiais estruturados, destacam-se o geoplano, material dourado, ábacos, tangram, potenciárea, materiais de seriação e classificação, sólidos geométricos, metro cúbico (de madeira), decímetro cúbico (de acrílico), metros quadrados (de jornal), quebra-cabeças, etc. A problemoteca", de acordo com Smole e Diniz (2001), apresenta sugestões de problemas com mais de uma solução e/ou sem solução, problemas de lógica, com excesso de dados e problemas não convencionais.

O LEPEM possui desafios para as diferentes faixas etárias (Figura 5). É possível citar, dentre os mesmos, formar, com bolas agrupadas de diferentes maneiras, uma pirâmide regular; formar, com peças irregulares, um cubo; formar, com peças irregulares, uma esfera; montar com TES um quadrado; Cubo Mágico das Engrenagens, etc.

Figura 5 - Alguns desafios existentes no LEPEM

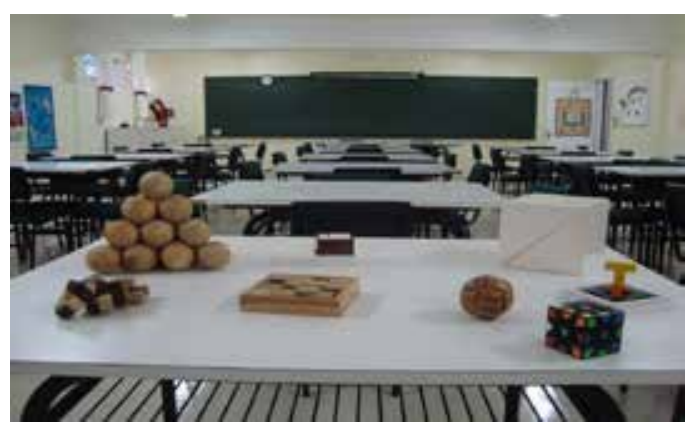

Fonte: A autora (2017)

A fim de possibilitar ao professor o desenvolvimento de suas atividades, o LE- 
PEM possui, ainda, recursos como seringas, embalagens diversas, jornais, transferidores, compassos, esquadros, trenas, réguas, colas, lápis de cor, massa de modelagem e um acervo de livros de Ensino Fundamental e Médio, entre outros.

As atividades desenvolvidas no LEPEM são voltadas ao ensino, à pesquisa e à extensão. Dentre as atividades desenvolvidas é possível destacar aulas para alunos da Escola Básica da URI Erechim, aulas para acadêmicos dos cursos de Licenciatura e Engenharia, confecção de jogos matemáticos e materiais alternativos, desenvolvimento de minicursos e projetos de extensão e iniciação científica.

O LEPEM conta com o auxílio de estagiário, o qual, entre outras atividades, separa os materiais solicitados pelos professores, confere os mesmos quando devolvidos ao Laboratório e produz recursos didáticos necessários. A definição de quais recursos são necessários ao LEPEM é feita quinzenalmente, em reunião com a professora responsável. Tal definição baseia-se nas necessidades dos professores da Escola Básica da URI Erechim, na observação dos materiais existentes no LEPEM, verificando se devem ser refeitos; na avaliação da necessidade de confeccionar um novo material e na necessidade de atender com excelência os acadêmicos das licenciaturas que, atualmente, usam os materiais do LEPEM para seus estágios.

Acreditando-se na importância que o Laboratório de Matemática pode representar no processo de ensino e de aprendizagem de Matemática, entre os anos de 2009 e 2011 realizou-se uma pesquisa de Iniciação Cientifica $^{4}$ envolvendo 23 escolas públicas localizadas na zona urbana do município de Erechim. Buscava-se, fundamentalmente, respostas a três questionamentos, a saber: 1) O Laboratório de Matemática tem sido uma estratégia de qualificação do ensino nas Escolas do município de Erechim? 2) Laboratórios de Matemática estão sendo uma alternativa concreta de ensino ou ainda permanecem como um ideal a ser alcançado pelas escolas? 3) Quais as dificuldades encontradas para sua implementação e funcionamento? Ao findar a pesquisa, constatou-se que o Laboratório de Matemática era um desejo dos professores, pois apenas uma escola possuía o espaço destinado à criação do Laboratório de Matemática, mas não possuía materiais e uma possuía um armário com rodinhas onde eram acondicionados os mesmos. Segundo os professores, as escolas não possuem Laboratório de Matemática por falta de espaço na escola para construí-lo, por falta de tempo e conhecimento para implementarem o mesmo e por falta de recursos financeiros.

Os dados coletados geraram inquietação entre os professores que trabalhavam as disciplinas pedagógicas no curso de Matemática, visto que os acadêmicos do referido curso, num futuro não longínquo, estariam atuando nas escolas da região, as quais não possuíam Laboratório de Matemática. Foi então que se pensou em algumas estratégias de ensino:

- Criação de recursos didáticos feitos de materiais alternativos.

- Criação e/ou recriação de jogos matemáticos feitos com materiais de baixo custo.

- Proporcionar cursos de extensão para os professores da rede pública da região da $15^{\text {a }} \mathrm{CRE}$ e das escolas municipais de Erechim.

$\mathrm{Na}$ sequência, serão descritas, de forma sucinta, cada uma destas atividades.

\section{Materiais alternativos}

Junto às demais atividades realizadas no LEPEM, o estagiário foi desafiado a pensar na produção de recursos didáticos feitos de materiais alternativos ${ }^{5}$, pois um dos motivos apresentados pelos professores para a não existência do LEPEM, nas escolas, é a falta de verbas para a compra dos mesmos. 
Apresentam-se, a seguir, alguns recursos didáticos feitos de materiais alternativos, tais como balança de dois pratos, jogo do general e ábaco.

\section{Balança}

A balança de dois pratos, recurso usado para introduzir a noção de medida de massa e equação de $1^{\circ}$ grau, foi confeccionada com rolos de papel toalha, caixa, areia, argola de metal, arame, tábua e embalagem de enlatado (Figura 6). A maior dificuldade encontrada na confecção foi o equilíbrio dos pratos da balança.

Figura 6 - Balança confeccionada com material alternativo

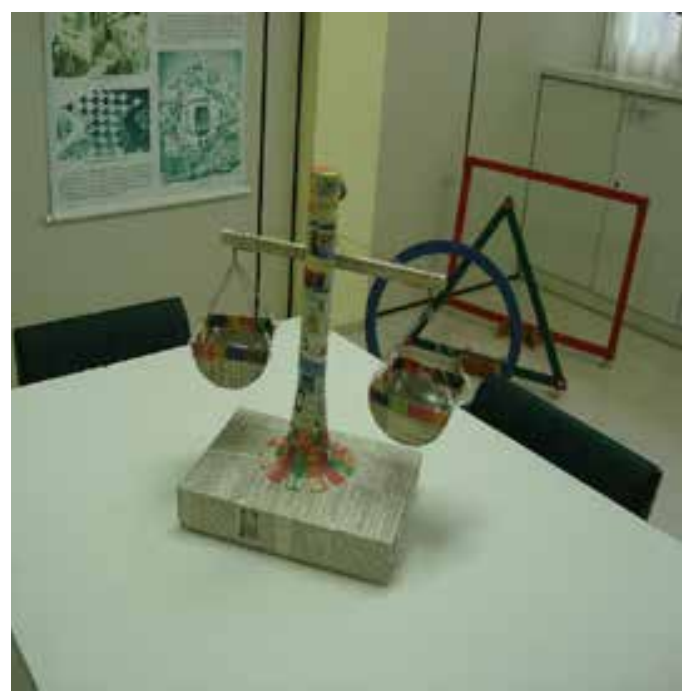

Fonte: A autora (2017)

\section{Jogo do General}

Não houve dificuldades na construção do Jogo (Figura 7), apenas algumas dúvidas em relação à escolha do material do "copinho" que compõe o mesmo. Após algumas tentativas, copo descartável, copo de vidro, optou-se pela lata de refrigerante.
Figura 7 - Jogo do general construído com material alternativo

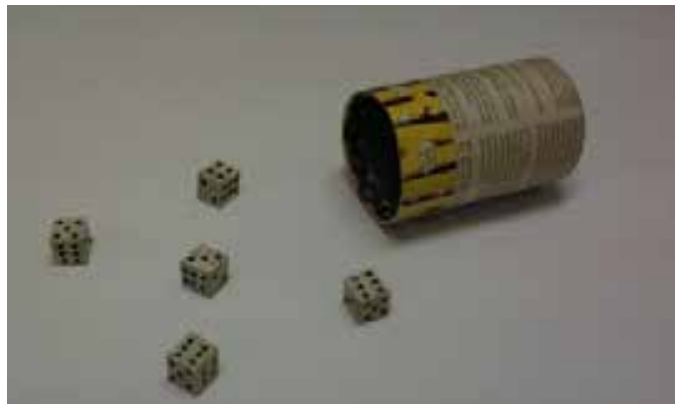

Fonte: A autora (2017)

O jogo do general ajuda na elaboração de estratégias, tomada de decisões e concentração. Além disso, ao confeccionar os dados deste jogo pode-se explorar as ideias do desenho geométrico, trabalhando com paralelas e perpendiculares, uso de compasso e esquadros, e na decoração do copo podem ser exploradas noções de simetria.

\section{Ábaco}

O ábaco, normalmente utilizado na Educação Infantil e nos Anos Iniciais do Ensino Fundamental, serve para trabalhar as noções de adição, subtração, multiplicação e divisão e as noções de unidade, dezena, centena e unidade de milhar (Figura 8).

Figura 8 - Ábaco construído com material alternativo

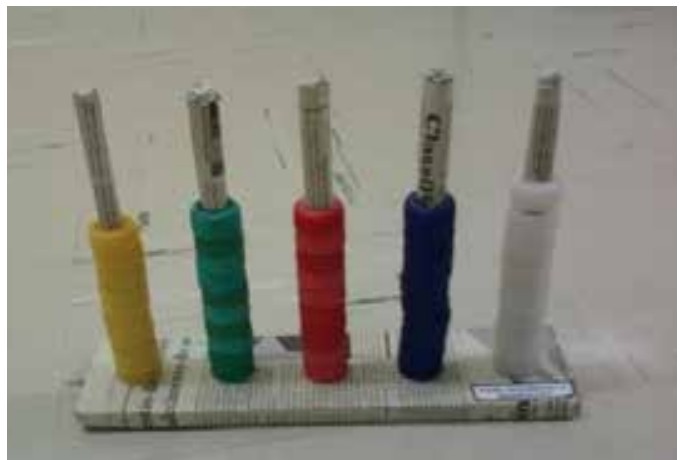

Fonte: A autora (2017) 
A confecção da base e das hastes do ábaco não ofereceu dificuldades. No entanto, o mesmo não ocorreu em relação às argolas. Primeiramente foram testadas argolas feitas com rolos de papel toalha, mas as mesmas não paravam umas sobre as outras, o que dificultaria a utilização do material, por isso optou-se por utilizar tampinhas de garrafa pet furadas no centro, conforme pode se observar na Figura 8.

Além dos materiais apresentados, foram confeccionados, a partir de materiais alternativos, discos fracionários, tábua de frações, sólidos geométricos e bingo (Figura 9).

Figura 9 - Recursos didáticos confeccionados com material alternativo

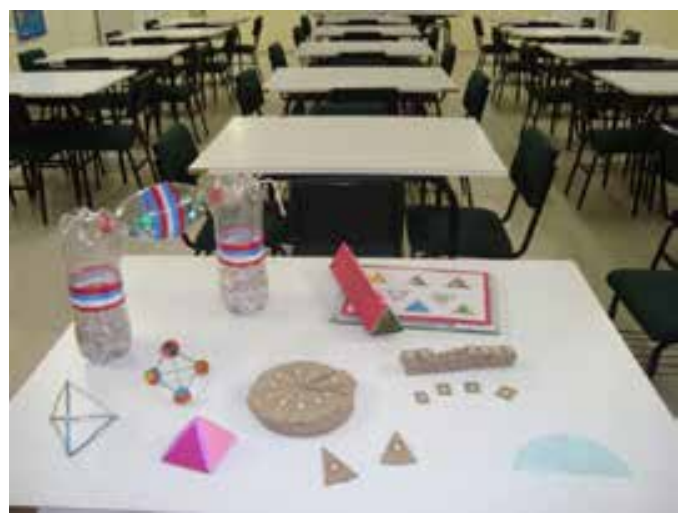

Fonte: A autora (2017)

\section{CRIAÇÃO E/OU RECRIAÇÃO DE JOGOS MATEMÁTICOS}

Buscando preparar os alunos para sua futura atuação profissional, e a implementação, caso necessário, de um Laboratório de Matemática, realizou-se, no decorrer das aulas das disciplinas de "Laboratório de Ensino de Matemática", na URI Erechim, uma atividade de criação e/ou recriação de jogos para trabalhar conteúdos de Matemática do $6^{\circ}$ ao $9^{\circ}$ ano do Ensino Fundamental, com materiais de baixo custo ou sucatas.

Um dos jogos criados pelos acadêmicos foi o "Dorminhoco matemático", o qual visa a aprimorar o cálculo mental e a tabuada. Foi recriado inspirando-se no jogo "Dorminhoco". Consiste na busca por realizar operações matemáticas entre as cartas que o jogador possui na mão (três) e as cartas que estão viradas sobre a mesa (duas), sendo que ambas as operações, entre as cartas que estão na mão e as que estão mesa, devem resultar no mesmo valor. Isso tudo feito com agilidade e discrição, de modo que o último aluno a perceber que foram obtidos os dois resultados iguais será o dorminhoco.

\section{OFICINAS PARA OS PROFESSORES DE MATEMÁTICA - Projeto de Extensão}

No ano de 2016, desenvolveu-se um projeto de extensão denominado "Criação e Implementação de Laboratório e Materiais Didáticos para o Ensino de Matemática", sendo que o mesmo acontecia uma vez por mês e atendia professores da $15^{\mathrm{a}} \mathrm{CRE}$, do estado do Rio Grande do Sul, alunos do curso de graduação em Pedagogia, vinculados ao programa PIBID e alunos do curso Normal (Figura 10).

O projeto visava a refletir sobre a importância que o Laboratório pode ter no processo de ensino e aprendizagem de Matemática, bem como explorar materiais didáticos $\mathrm{e}$ jogos matemáticos e construí-los.

No primeiro encontro do ano, os participantes do projeto foram desafiados a criar um Laboratório de Matemática na escola em que atuavam, seja como aluno, estudante ou estagiário. Por isso, ao findar o mesmo, 
os participantes apresentaram como estava ocorrendo a implementação do Laboratório nas escolas, destacando-se, assim, as metas alcançadas e os problemas encontrados. Foram implementados quatro Laboratórios de Matemática. Além disso, os alunos do Curso Normal ${ }^{6}$ que já possuíam Laboratório de Matemática em sua escola (o qual foi construído pelos alunos pibidianos do curso de Matemática da URI Erechim), continuaram implementando o mesmo, ampliaram o acervo e criaram estratégias de controle dos materiais.

Figura 10 - Encontros do projeto de Extensão
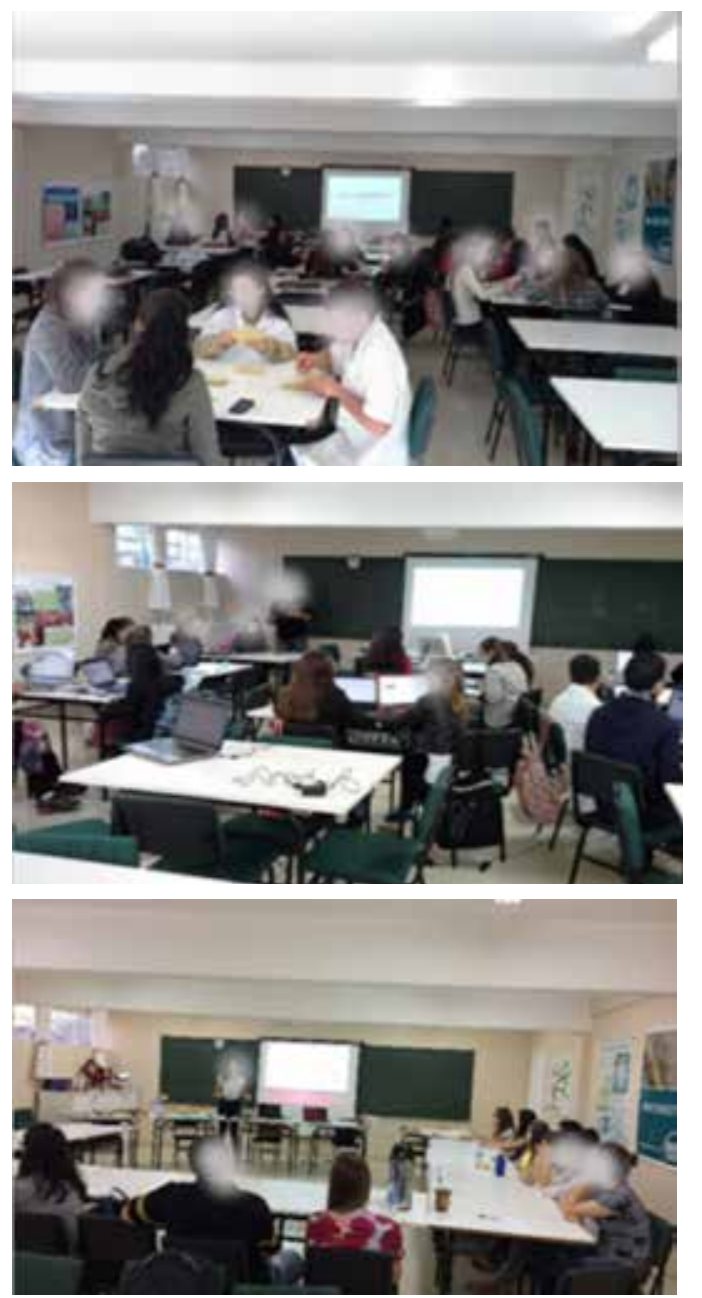

Fonte: A autora (2017)

\section{Considerações finais}

O processo de implementação do LEPEM na URI Erechim foi muito trabalhoso, exigiu dedicação e empenho, porém todo o esforço dedicado é recompensado quando percebe-se que o mesmo tornou-se um recurso muito importante no processo de ensino e aprendizagem dos alunos, tanto da escola básica quanto dos acadêmicos de graduação, já que o manuseio e exploração dos materiais existentes neste espaço facilitam o entendimento dos conceitos matemáticos e os jogos auxiliam na fixação dos mesmos.

As atividades realizadas no LEPEM da URI Erechim continuarão sempre voltadas a auxiliar os alunos e professores na construção do conhecimento matemático. Por isso, serão realizadas, continuamente, atividades de confecção de materiais, assessoramento aos professores e alunos da região na qual a instituição atua, bem como atividades voltadas à pesquisa. 


\section{NOTAS}

${ }^{1}$ Pré-escola hoje denominada Educação Infantil.

2 Pedagogia Séries Iniciais hoje denominada Pedagogia Anos Iniciais.

${ }^{3}$ Escola Básica de $1^{\circ}$ e $2^{\circ}$ Graus da FAPES, hoje denominada Escola de Educação Básica da URI Erechim

4 A Pesquisa de Iniciação Científica foi realizada de agosto de 2009 a julho de 2011 em todas as escolas estaduais da zona urbana e rural do perímetro urbano de Erechim, RS. Era intitulada por "O Laboratório no Processo Ensino-Aprendizagem de Matemática no Município de Erechim-RS" e tinha como objetivo principal verificar a existência do Laboratório de Matemática nas referidas escolas e a concepção dos professores de Matemática sobre este ambiente de aprendizagem.

${ }^{5}$ Entendem-se materiais alternativos como aqueles que normalmente são descartados, ou seja, as sucatas: caixas, potes, rolos de papel, cones de linha, tampas de garrafas pet, etc.

${ }^{6}$ O curso Normal Médio, garantido pela Lei de Diretrizes e Bases da Educação (LDB 9394/96), possibilita o aprofundamento de conhecimentos, competências e habilidades e forma docentes para o exercício da atividade na Educação Infantil e nos Anos Iniciais do Ensino Fundamental.

\section{REFERÊNCIAS}

BRASIL. Ministério da Educação. Base Nacional Comum Curricular - Educação é a base. Brasília, 2017.

EWBANK, W. A. The mathematics laboratory: what? why? when? how? NCTM. Alberta, 1997. GONÇALVES, A. R. O Uso do Laboratório no Ensino da Matemática. Disponível em: http:// www.reisdofaroeste.com.br/pacoca/artigo_laboratoriodeensinodematematica.pdf. Acesso em: 14 maio 2011

LORENZATO, S. Laboratório de ensino de matemática e materiais didáticos manipuláveis. In: LORENZATO, S. (Org.). O laboratório de ensino de matemática na formação de professores. Campinas, SP: Autores Associados, 2006. p. 3-37. (Coleção Formação de Professores).

OSHIMA, I. S.; PAVANELLO, M. R. O Laboratório de Ensino de Matemática e o Ensino da

Geometria. Disponível em: http://www.diaadiaeducacao.pr.gov.br/portals/pde/arquivos/232-4.pdf. Acesso em: 12 maio 2011.

PEREZ, G. O Laboratório de Ensino e os Materiais Didáticos no Ensino de Matemática. UNESP, Rio Claro/SP, Abril de 1993, (manuscrito).

REFOSCO, M. I.; BASSOI, T. S. O Laboratório de Ensino de Matemática nas Escolas Públicas do Paraná e as Concepções dos Professores. Disponível em: http://www.diaadiaeducacao.pr.gov. br/portals/pde/arquivos/847-4.pdf. Acesso em: 14 maio 2011.

RÊGO, R. RÊGO, R. Desenvolvimento e uso de materiais didáticos no ensino de matemática. In: LORENZATO, S. (Org.). O laboratório de ensino de matemática na formação de professores// Campinas, SP: Autores Associados, 2006. p. 39-56. (Coleção Formação de Professores). 
SILVA, R. C.; SILVA, J. R. O Papel do Laboratório no Ensino de Matemática. In: Encontro Nacional de Educação Matemática, 8., 2004, Pernambuco. Anais [...] Pernambuco: UFP, 2004.

SMOLE, K.S. DINIZ, M.I. (orgs). Ler, escrever e resolver problemas: habilidades básicas para aprender matemática. Porto Alegre: Artmed, 2001. 